\title{
Problemas textuales en la poesía de Jorge Manrique
}

\author{
Textual Problems in the Poetry of Jorge Manrique
}

\author{
Bienvenido Morros Mestres \\ Universidad Autónoma de Barcelona \\ bienvenido.morros@uab.es
}

ORCID iD: https://orcid.org/0000-0002-4285-1079

RESUMEN: El presente trabajo estudia diferentes problemas textuales de la poesía de Jorge Manrique. En primer lugar, pretende resolver la conflictiva adiáfora de las $\mathrm{Co}$ plas a la muerte de su padre al hallar la fórmula recordada por el autor ("perdido el uso de los sentidos") en las oraciones para moribundos. En segundo lugar, llama la atención sobre dos lecciones de uno de sus poemas amorosos para sugerir las enmiendas oportunas con las herramientas que proporciona la crítica textual más tradicional.

Palabras clave: poesía medieval, siglo $\mathrm{xV}$, bestiarios medievales, ars moriendi, ecdótica.

ABSTRACT: The present work studies textual problems of the poetry of Jorge Manrique. First of all, it intends to resolve the controversial adiáfora of the Coplas a la muerte de su padre by finding the formula to remember the "perdido el uso de los sentidos" in prayers for the dying. Second, it draws attention to the lessons of one of his love poems to suggest the opportune amendments with the tools that offer the most traditional textual criticism.

Keywords: medieval poetry, $15^{\text {th }}$ century, medieval bestiaries, ars moriendi, ecdótica.

La poesía de Jorge Manrique sigue suscitando controversias en su misma transmisión porque los testimonios que la han conservado o bien difieren en sus lecturas o bien no han sido rigurosos a la hora de editar o copiar sus versos. En estas páginas analizaremos una de esas variantes, producida en su obra más conocida, las Coplas a la muerte de su padre, y las lecturas conflictivas que se 
han ofrecido del poema con el que abre sus "Obras de amores" el Cancionero General de Hernando del Castillo. Lo haremos en dos partes bien diferenciadas porque los poemas en cuestión ilustran problemas de crítica textual de índole muy distinta al tener una transmisión también muy dispar e independiente.

\section{I}

Las Coplas a la muerte de su padre plantean un dilema textual que ha dividido a sus editores en dos grupos bien diferenciados: los que adoptan una variante y los que siguen otra en las lecciones enfrentadas que los testimonios han conservado de un verso del poema. Esas dos lecturas contrapuestas se dan en la estrofa, la cuarenta y última, en que el autor narra el momento de la muerte de su padre en su lecho y rodeado de sus seres más queridos (tanto parientes como criados). Antes de entregar su alma a Dios el moribundo ha tenido aún la clarividencia suficiente para dirigir una oración a Jesucristo, pero una vez la ha acabado no queda claro si mantiene o no esa clarividencia:

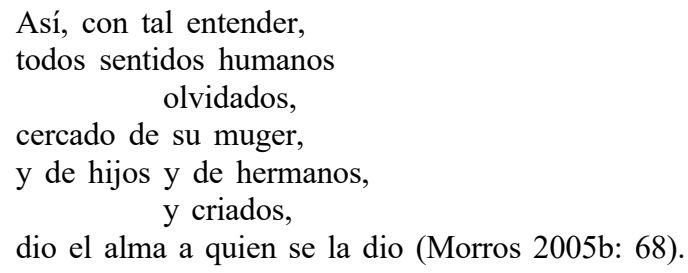

Otros testimonios traen "conservados" en el lugar de "olvidados", y las dos lecturas se reparten entre las dos ramas altas del stemma, una representada por $B b G$, que reproducen la segunda, y otra por $C a c d$, que registran la primera, como puede comprobarse en el stemma elaborado por Beltrán, del que solo transcribo las ramas altas (Beltrán, 1991: 80):

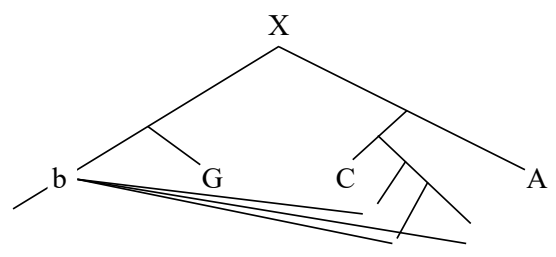

El testimonio $A$ no cuenta para esta lectura porque ha perdido el folio, el último, en el que debía aparecer copiada la copla en cuestión (ibíd.), pero el resto de testimonios ilustra el caso de lecturas adiáforas, las que en un stemma 
bífido poseen las mismas posibilidades, un cincuenta por ciento, de constituir la lectura del arquetipo y también la correcta (Blecua, 1983: 104). La adiaforía, de no presentar variantes de autor, no es fácil de resolver porque los editores aplican sus juicios críticos para defender una u otra lección, y los juicios críticos no suelen ser infalibles en los análisis de las variantes. En nuestro ejemplo llama la atención que las tres ediciones que incluyen las coplas manriqueñas entre las de fray Iñigo de Mendoza discrepen también en ese pasaje: $b$ frente a $c$ y $a$, a las que en otros lugares contamina. Conde 2009 utilizó esta variante para reflexionar sobre los límites del método neolachmaniano, insuficiente para resolver este tipo de problemas textuales: recurrió también a la conformatio textus para llegar a una conclusión distinta a la que voy a defender en las siguientes páginas (aunque los ejemplos que trae a colación, como podremos comprobar, no descartan mi hipótesis). Más recientemente Beltrán (2016) ha insistido sobre la acepción "sentidos humanos" para defender, como ya había hecho en sus ediciones, la lectura "olvidados" y hacer de paso interesantísimas observaciones sobre el criterio de la lectio difficilior.

Manrique emplea la alegoría de la muerte como un personaje que llama a la puerta de la casa de su padre, a quien presenta en actitud complaciente y nada rebelde ante su llegada. El moribundo se dispone a recibirla con una oración en voz alta a Jesucristo para pedirle el perdón de sus pecados y la salvación eterna, siguiendo, como veremos, las pautas previstas en las ars moriendi. Es precisamente en ese último momento, cuando ha terminado la oración y ya va a morir, en el que ha podido olvidar o conservar sus sentidos humanos. Para unos es lógico que el moribundo esté privado de los sentidos humanos al recibir la muerte mientras que para otros resulta comprensible que los conserve hasta el último instante en prueba de su lucidez ${ }^{1}$. Para intentar resolver esta duda procedamos por partes y analicemos con detalle el final del poema.

El moribundo tras oír a la muerte decir que ha venido para llevárselo eleva una oración a Jesucristo recordando su sufrimiento en la cruz para redimir a la humanidad. En ese momento no sólo está aún en uso de sus facultades mentales sino también del sentido del habla, porque de lo contrario no habría podido hacer ese esfuerzo físico e intelectual, tal y como aclaran las ars moriendi: "Si el que está en la agonía e artículo de la muerte pudiere fablar e usar de la razón, trabaje por ocuparse en oraciones"2.

\footnotetext{
${ }^{1}$ Entre estos últimos se encuentra Morrás (2003: 278, n. 470), quien interpreta en primera instancia "sentidos" como los 'corporales', pensando que el moribundo los conserva hasta el último momento de su vida, en concordancia con "las artes moriendi y con el ideal estoico". Es obvio que el moribundo ha de conservar la razón y el juicio para bien morir pero cuando le llega ya la muerte empieza por perder los cinco sentidos del cuerpo.

${ }^{2}$ Para el Arte de bien morir uso la edición de Gago Jover (1999: 117). Conde (2009: 73), aduce, entre otros, el texto que narra la muerte de Alonso de Cartagena para defender la lectura
} 
El padre de Manrique se ocupa de sus oraciones y muere tranquilamente porque no ha sido interrumpido por ninguno de sus familiares reclamándole una parte de la herencia. En el primer verso de la última copla el hijo alude precisamente a esa situación en que su padre ha podido dedicar su pensamiento exclusivamente a la oración y a la propia salvación: “Así, con tal entender", 'Así, con tal ocupación o pensamiento'. Don Rodrigo se ha librado de las distracciones que solían sufrir los moribundos, que llegaban a hacer peligrar su salvación, como denuncian los autores de las ars moriendi:

Porque comúnmente aun los enfermos no piensan de morir, e por quanto el marido o la muger restante, e los fijos e parientes que entienden de heredar sus bienes, más procuran a lo induzir a su amor, llorándolo por que les dexe más bienes [...] E assí, muchas vezes, las ánimas de los morientes miserablemente se peligran ${ }^{3}$.

El alma de don Rodrigo no ha peligrado en ningún momento porque ha podido ocuparse de su salvación y no de otras cuestiones mundanales. Antes de morir ha podido rezarle, como hemos podido comprobar, una oración a Jesucristo, y en esa oración puede estar la clave de los versos siguientes: "todos los sentidos humanos/ olvidados" (o "conservados").

En el siglo XIII ya existían cofradías que "orientaban sus devociones a la preparación para la muerte" con oraciones específicas, como el Ave María, de petición de ayuda en el último aliento de vida. En las ars moriendi medievales conservadas se mencionan las diferentes oraciones que el moribundo puede rezar una vez llegado a ese punto, pero no reproducen su contenido completo. La primera oración recomendada era la dirigida a Dios para suplicarle "que tenga por bien de rescibir a él en su gloria, por la su sanctísima e maravillosa misericordia e por la virtud de su pasión" (Gago, 1999: 119). La segunda aconsejada era la dedicada a la Virgen María para pedirle que ejerza el papel de abogada y mediadora en su salvación. La tercera sugerida era la consagrada a los ángeles, apóstoles y santos, especialmente a los que el enfermo tenía una devoción especial.

\footnotetext{
"conservados": "Illico mandauit ut coram eo ipso audiente recitarentur ibi pasiones quas dominus noster Iesus Christus pro nobis peccatoribus passus est ut saluaret nos [...] Et sic integru sensu petiuit sibi dari candelam, quam in sua manu recipiens et crucem in alia, Semper ymaginem Crucifixi aspiciens, inter ipsa uerba orationis inter manus suorum simpliciter oculos claudendo obdormiuit in Domino". El moribundo ordena que le reciten las oraciones sobre la muerte de Jesucristo y reclama un crucifijo para morir con él entre las manos: en esta primera fase ha tenido el juicio intacto para en la última y final acabar cerrando los ojos. Don Rodrigo también evoca, teniendo asimismo el juicio intacto, los tormentos de Jesús en la cruz para en el último momento, el de la agonía, perder el mundo de vista y morir: es el momento de la muerte en que pierde u olvida los sentidos, no antes.

${ }^{3}$ Beltrán, 1991: 158, y 1993: 229, recuerda este pasaje del Arte de bien morir junto a otro del Tratado de la consolación de Enrique de Villena para documentar la preferencia de la muerte cristiana en la cama frente a la muerte repentina y desprevenida.
} 
En 1648 el séptimo padre general de la Compañía de Jesús, Vicente Caraffa, erigió la Asociación del Santísimo Cristo de la Agonía y de la Virgen de los Dolores, llamada comúnmente de la Buena Muerte. Es una congregación que, creada con la misma finalidad que las cofradías medievales, incluían las oraciones completas que podían rezar los moribundos a la hora de su muerte (Revuelta, 2008: 638). Los jesuitas desde la fundación de su orden habían compuesto diversos manuales sobre la buena muerte a imitación de las ars moriendi medievales (Francisco de Borja y Juan de Polanco fueron dos de los autores más importantes), y tras la institución de su congregación, pusieron por escrito unos ejercicios de preparación que dieron a conocer con el título Instrucción a los individuos de la Congregación de la Buena Muerte (Madrid, 1832) ${ }^{4}$. El ejercicio más importante consistía en la memoria de la pasión y muerte de Jesucristo, que culminaba con unas "súplicas a Jesús crucificado" que debían pronunciar los agonizantes en su último instante de vida: "Cuando perdido el uso de los sentidos desaparezca todo el mundo de mi vista, y gima entre las últimas agonías y afanes de la muerte, Jesús misericordioso, tened compasión de mí” (1833: 53).

Estas "súplicas" se refieren al momento inmediato a la muerte en que el moribundo pierde el mundo de vista y ya no se rige por sus sentidos: es para ese último segundo de vida que el moribundo debe pedir la compasión y misericordia de Jesús. Don Rodrigo obra de la misma manera al acabar su súplica a Jesús y recordar su suplicio en la cruz: "mas por tu sola clemencia,/ me perdona" (XXXIX, 466-467); sin apenas tiempo para nada más, muere, y su muerte está introducida por la misma fórmula, "los sentidos humanos/ olvidados" en un caso, "perdido el uso de los sentidos" en el otro.

La relación entre ambos textos es muy evidente pero el problema es que no he podido documentar esas "súplicas" en la época de nuestro autor, pero sí, en cambio, la fórmula "perdido el uso de los sentidos", que un poco simplificada ya aparece en las anónimas Danzas de la muerte, de principios del siglo XV, en un contexto afín de despedida. El rey, ante la invitación hecha por la muerte a danzar con ella, cobra conciencia del inminente final de su vida, que describe con la expresión "perder los sentidos"":

Mas ¿qué es aquesto que veo en balanza acortarse mi vida e perder los sentidos?

El cor se me queja con grandes gemidos.

Adiós mis vasallos, que muerte me trança (XVIII, 5-8; Solà-Solé 1981: 39) ${ }^{6}$.

\footnotetext{
${ }^{4}$ Véanse sobre el tema Morel D’Artieux (1990: 729), y Burrieza Sánchez (2004: 146-149).

${ }^{5}$ Para la influencia de las danzas de la muerte en las coplas de Manrique sigue siendo fundamental la obra de Víctor Infantes (1997: 111-113).

${ }^{6}$ La edición sevillana de 1520 reproduce esos versos con mínimos cambios: “¿Mas qué es aquesto,/ que veo en balança/ estar mi vida, perder mis sentidos?/" (Solà-Solé, 1981: 57).
} 
Es posible que al autor castellano haya podido conocer el poema $\mathrm{V}$ del género de los Trois morts et des trois vifs, trasmitido por seis manuscritos repartidos entre los siglos XIV y XV. Los cincos poemas reproducen la misma situación de tres cadáveres en descomposición dirigiéndose a tres caballeros jóvenes para introducir los tópicos habituales del género, como los del memento mori de la buena muerte. En el poema V los caballeros intervienen una vez lo han hecho los tres cadáveres. Es el primer caballero, el primer vivo, el que recurre a la fórmula en cuestión, pero en singular, tras solicitar la protección de la Santa Cruz:
O sainte crois, par ta poissance
dont je voy cy la remanbrance,
garde mon corps e ne consens que
je perde au jour d'uy mon sens
pour cest gent hideuse et morte,
qui telz nouvelez nous apporte
(vv. 179-184; Glixelli 1914: 101-102).

Diego de San Pedro, en su famosa Cárcel de amor, recuerda parcialmente la fórmula porque la reduce a dos de los sentidos, el del habla y el de la vista, en un contexto menos religioso y más pagano. El protagonista de la obra, Leriano, ha decidido poner fin a su vida dejándose morir de hambre, y estando ya cerca de la muerte aún tiene fuerzas suficientes para defender a las mujeres de los ataques que les había dedicado su amigo Tifeo. Es precisamente al terminar su discurso, equivalente a la oración de don Rodrigo Manrique, cuando empieza a perder los sentidos, empezando por el habla y la vista: "El qual quando acabó de hablar tenía ya turbada la lengua y la vista casi perdida" (Parrilla, 1995: 76-77) ${ }^{7}$.

La fórmula en los términos completos fue empleada y también explicada por el anónimo traductor al castellano de la Imagen de la vida cristiana (Zaragoza, 1571) del jerónimo portugués fray Héctor Pinto:

Estando para morir un hombre hace su testamento y albaceas; acercándose la muerte, pierde el calor natural y pierde el uso de los sentidos, de manera que ni oye ni ve ni habla hasta que muere (Glaser, 1967: 258).

El conde-duque Olivares, don Gaspar Gómez y Pimentel, incluyó también la fórmula en su testamento, redactado en 1642, dentro de la súplica dirigida a Jesucristo para pedirle en el último instante de vida la compañía adecuada que le ayude a bien morir:

\footnotetext{
${ }^{7}$ El pasaje también ha sido aducido por Conde, 2009: 74, para justificar la lectura "conservados", pero creo, modestamente, que ilustra la otra lectura, la de "olvidados", en tanto "perdida la vista" constituye una variante de la fórmula "perdido el uso de los sentidos".
} 
y suplico a nuestro señor Jesucristo que así como a la entrada de esta vida me ayudaron a creer mis padrinos porque no tenía uso de razón, así a la salida, cuando estuviese privado del uso de los sentidos, me ayuden a creer todos los circundantes (Matilla Tascón, 1983: 171).

La fórmula se acabó integrando a finales del siglo XVII en los manuales de la buena muerte compuestos en torno a la congregación de los jesuitas para describir precisamente ese último aliento de vida del moribundo, pero desvinculado de las "súplicas a Cristo crucificado". El primero de estos manuales fue el Directorio para bien morir. Ejercicios que practica la ilustre y venerable congregación de nuestra señora de la buena muerte erigida en esta ciudad de Barcelona en el año 1700:

Cuando rendidas las fuerzas, cuando perdido el uso de los sentidos, oscurecido el entendimiento y oprimido el corazón de mortales congojas, temblando el hombre de pies a cabeza, sucumbe al último golpe que le desata el alma del estrecho vínculo que la tenía unida con el cuerpo (Anónimo, 1864; 218) .

En los concilios del siglo XVIII y las guías para sacerdotes del siglo XIX se introdujo constantemente la fórmula para dejar claro en qué circunstancias debían darse la extremaunción y la absolución al moribundo: si antes o después de la pérdida del uso de todos sus sentidos. Desde las danzas de la muerte la fórmula se había empleado siempre con el mismo significado en la situación del artículo de la muerte, y solos los místicos lo habían variado levemente al utilizarla para referirse a sus estados de alienación o embelesamiento?.

Manrique utiliza la fórmula "todos los sentidos humanos/ olvidados" en relación directa con "dio el alma a quien se la dio" para narrar la progresiva pérdida de sensibilidad y conciencia de su padre hasta su muerte: otorga a la fórmula la función de ablativo absoluto que introduce la oración principal de la copla entera. El moribundo entra en un trance comatoso, previo al fatal desenlace, en el que ya no habla ni ve ni oye; hasta ese momento ha conservado la conciencia pero una vez ha salvado su alma con la oración a Jesucristo empieza a perder de manera evidente los sentidos corporales o externos hasta expirar en la agonía final el último aliento de vida: "todos los sentidos humanos/ olvidados [...]/ dio el alma a quien se la dio" ("teniendo todos los sentidos humanos olvidados, y estando rodeado de parientes..., murió'). El hijo pudo haber aprendido la fórmula, en la que ha cambiado el verbo por exigencias de rima ("per-

\footnotetext{
${ }^{8}$ También registra la fórmula más tradicional después de la petición de misericordia a Jesucristo: "Cuando perdido el uso de los sentidos, el mundo desaparezca de mi vista, y gemiré entre las angustias de la última agonía" (Anónimo, 1864: 21).

${ }^{9}$ Así lo hace, por ejemplo, Santa Teresa de Jesús en Las moradas del castillo interior: "Que verdaderamente parece que el alma se aparta del cuerpo, porque se ve perder los sentidos y no entiende para qué" (Chicharro, 1999: 375).
} 
dido" por "olvidado"), de las danzas de la muerte o de alguna oración similar a las recogidas posteriormente por los manuales sobre la buena muerte de los jesuitas (el que las artes medievales no la incluyan no significa que no pudiera formar parte de la tradición oral).

Esta explicación de una de las lecciones enfrentadas o adiáforas debería descartar definitivamente la otra: en ese punto agónico de vida, confortado por los suyos y habiendo recibido la absolución, no parece demasiado lógico que don Rodrigo mantenga intactos "todos los sentidos humanos", en especial los cinco corporales, porque está abandonando este mundo (los sentidos afectados son los sentidos que mueren con el cuerpo pero no con el alma). La lección "conservados" tiene el aspecto de una lectio facilior al pretender con su introducción dignificar más al moribundo subrayando su conciencia y lucidez hasta el último instante de vida, pero la lección "olvidados" no es incompatible con la lucidez intelectual del moribundo sino con su comunicación con el mundo sensible $^{10}$. En este caso la variante adiáfora y equipolente (una lo es en el stemma y la otra en la recensio) no tienen ya las mismas posibilidades de remontarse al arquetipo ni menos al original: matemáticamente sí, pero no desde el punto de vista filológico. Tras la aplicación del iudicium, la variante en cuestión pierde por tanto la condición de equipolente.

La poesía amorosa de Manrique plantea otro tipo de problemas textuales porque tuvo también una transmisión independiente al de las Coplas a la muerte de su padre. El corpus más importante de ese tipo de poesía lo imprimió Hernando del Castillo en la segunda parte de su Cancionero General, parte que se acabó llamando "Obras de amores", en lugar del original "Obras de autores", en la que el compilador acopla "varios cancioneros o cancionerillos individuales" (González Cuenca, 2004a: 42). Como sostiene Beltrán, es posible que Hernando del Castillo tuviera acceso o pudiera disponer de un cancionero completo de Manrique, especialmente de la obra amorosa (Beltrán, 1992: 170). De ser así, no es descartable la hipótesis de que el orden que ofrece Hernando del

\footnotetext{
${ }^{10}$ En su espléndida edición crítica, Beltrán (1991: 158, y también 1993: 229) se había decantado por la lección "olvidados" no solo al considerarla más difícil sino también al entender que en el pasaje encajaba mejor: "Prefiero la primera opción, pues sentido tiene la acepción 'apetito, o parte inferior del hombre' (Aut.), reforzado probablemente por el calificativo de humanos, lo que hace de esta variante un caso de lectio difficilior". A pesar de haber editado "conservados", siguiendo a Ángel Gómez Moreno (2000: 248), María Morrás reconoce que la lectura "olvidados", de interpretar "sentidos" como 'apetitos del cuerpo', podría ser en efecto difficilior (Morrás, 2003: 278, n. 470).
} 
Castillo quepa atribuírselo al propio autor: el compilador deshace parte de ese corpus al extraer de él bastantes poemas para repartirlos entre las secciones de canciones, motes glosados y villancicos. Es la partición por géneros que acaba presidiendo la edición de Castillo lo que "impide conocer con detalle cuál era la estructura original" del cancionero de Manrique.

Los poemas amorosos que han tenido otras fuentes de transmisión presentan variantes muy diferenciadas que podrían ser de autor. Sin embargo, yo me propongo estudiar uno de los poemas que solo ha conservado el Cancionero General, y como su texto en el caso de Manrique suele contener errores, según ya advirtió el propio Beltrán en su estudio comparativo con otros testimonios, he considerado oportuno llamar la atención sobre dos errores que he detectado en el poema en cuestión (Beltrán, 1992: 171).

El poema en el que he advertido esos dos errores es el que suele abrir el cancionero amoroso de Jorge Manrique en los dos testimonios impresos que lo han transmitido: las dos primeras ediciones del Cancionero General de Hernando del Castillo (11CG, fols. 96 v-97 r; 14CG, fol. 74 v; Dutton ID614011). El poema tiene la función de initium narrationis y por tal motivo es verosímil pensar que ya ocupaba el primer lugar en el cancionero de Manrique: en sus versos el poeta castellano narra su enamoramiento (primero de oídas) de una dama de la que al final ha de lamentar su ausencia por haber sido separado de ella. La parte final del poema es un juego, con la alegoría del martirio de san Vicente de Valencia, sobre la teoría ficiana del amor recíproco: los amantes que se aman mutuamente (y nuestro poeta parece ser también amado por su dama) dejan de vivir en sí mismos para hacerlo, tras una muerte simbólica, en la persona amada ${ }^{12}$. Los amantes correspondidos mueren para renacer en el otro, pero

\footnotetext{
11 Para identificar más fácilmente el texto y sus testimonios he usado la numeración y siglas de Dutton (1982).

12 Para la teoría ficiana aplicada a la literatura española, sigue siendo fundamental el libro de Serés, 1996. No es imposible, como ya sugerí en otro lugar (Morros, 2005a: 136), que Manrique hubiera conocido el comentario de Marsilio Ficino al Banquete de Platón, del que se han conservado tres versiones distintas, dos en latín y otra en italiano. Ficino compuso una primera versión en 1469, en colaboración con su amigo Giovanni Cavalcanti; en 1475, entregó a Lorenzo de Medici una segunda versión con modificaciones y con la división en capítulos; ya posteriormente tradujo la segunda versión latina al italiano (Villa, 1986: XVII-XVIII; véase también Byrne, 2015: 16-49). En estas coplas el poeta describe el encuentro con la dama poniendo énfasis en el intercambio de miradas, que parecen indicar correspondencia, si bien reconoce que todos sus sentidos "de sus fines no gozaron" (vv. 71-72), en alusión sobre todo al del tacto, descartado en los amores más puramente platónicos: "los ojos embebecidos/ fueron tan bien acogidos/ que del todo me alegraron" (vv. 73-75). En estos últimos versos podría incluso haber una referencia al intercambio de espíritus, propio de los amantes correspondidos. En la segunda quintilla de la "finida", Manrique invoca la llegada de su amada, en términos semejantes a cómo invocará a la muerte el comendador Escrivá, dejando claro que con su llegada él volverá a la vida: "venga ya, y verá mi vida,/ que se fue con vuestra ida" (vv. 118-119, Morros, 2005b: 9). Estos versos junto a otros de
} 
si han de separarse padecen también una muerte simbólica porque ellos viven no donde animan sino donde aman. El poeta, confiando en el regreso de su dama, presenta su cadáver custodiado por un león, símbolo de Jesucristo y de la resurrección, porque es plenamente consciente de que con la venida de la dama volverá a tener vida. En el momento en que ha sufrido la ausencia de la amada, que es por tanto la causa de su muerte simbólica, el poeta describe su sufrimiento en estos términos:

La crueza de mis males más se calla en la dezir, pues mis dichos no son tales, que igualen las desiguales congoxas de mi vevir (vv. 91-94).

Los dos primeros versos de la quintilla parecen recordar el conocido tópico de que los males se alivian al comunicarlos con algún amigo o persona de confianza, pero en este caso el tópico se contradice con la afirmación expresada en los tres versos siguientes e introducida por una conjunción causal, y no por una adversativa. En esos últimos versos el poeta da a entender que sus males son tan inefables que no pueden expresarse con palabras. Si esos males son tan inefables como asegura en los tres últimos versos sorprende que en los dos primeros haya afirmado que los ha podido expresar y que al hacerlo los haya podido disimular o incluso calmar. De interpretar esos versos en semejante sentido es evidente la contradicción con los otros versos de la quintilla, y solo hay una posibilidad de hacer compatibles unos versos con otros. Esa posibilidad cabe buscarla en un pasaje de la tragedia Fedra de Séneca en el que la protagonista parece no tener fuerzas ni palabras suficientes para reconocerle su amor a su hijastro Hipólito:

Sed ora coeptis transitum verbis negant. Vis magna vocem emittit, at maior tenet $[\ldots]$

Animusne cupiens aliquid effari nequit?

Curae leves loquuntur, ingentes stupent

(II, vv. 602-607; Séneca, 1832: 53) ${ }^{13}$.

las canciones "Es una muerte escondida" (v. 1, Beltrán, 1993: 117) y "No tardes, muerte, que muero;/ ven, porque viva contigo [...]/ con tu venida espero/ no tener vida conmigo" (vv. 1-2 y 14-15, Morros, 2005b: 34), constituyen la fuente fundamental de la paradoja del comendador "Ven, muerte, tan escondida,/ que no te sienta conmigo,/ porqu'el gozo de contigo,/ no de la muerte como si fuera de la amada, cuya presencia puede darle la vida que su ausencia le había quitado. Para el uso de esta paradoja en uno de los últimos poemas de Ángel González, véase Morros [en prensa].

${ }^{13}$ Para la influencia de Séneca en la poesía de Manrique, especialmente en las coplas a la muerte de su padre, sigue siendo fundamental Blüher (1983: 185-186). La traducción catalana, atribuida al valenciano Antoni de Vilaragut, introduce algunos cambios en el texto latino: "La mia boca nega lo passatge a las paraules mogudes, car la gran amor me toll la veu e la major vergonya 
('Pero la boca niega el paso a las palabras comenzadas. Una gran fuerza emite la voz, pero otra mayor la retiene [...] ¿Acaso el alma te niega expresar o hablar algo que deseas? Las preocupaciones leves hablan; las grandes nos dejan mudos').

Es posible que Manrique tenga el mismo problema que Fedra: 'la crueldad de mis males más se calla cuando intento decirla o comienzo a decirla porque mis males no pueden compararse con las palabras'. No es la prudencia la que impide hablar a Fedra sino la inefabilidad de lo que pretende decir, como anotan los estudiosos del poeta latino ${ }^{14}$. La madrastra de Hipólito prepara la voz para articular las palabras, pero en esa acción enmudece, no por miedo, sino por la dimensión y gravedad de sus penas de amor. Es exactamente lo que le puede ocurrir a Manrique al intentar expresar sus males: su lengua es incapaz de darles voz también por su gravedad o crueldad (en la acción de decirlos es cuando los males se silencian, se callan).

Sin embargo, teniendo en cuenta que "dezir" no tiene ese sentido incoativo que le hemos supuesto, podría suponerse en el pasaje un error cuya enmienda resulta muy sencilla: la sustitución de una letra por otra en la palabra ("más") que encabeza el segundo verso. El poeta podría haber escrito el adverbio de modo "mal", que algún copista, al confundir la ele con una ese alta, usada especialmente a final de palabra, como la sigma, convirtió en el adverbio de cantidad "más", por la disimilación con "males" del verso anterior y condicionado también por la formulación del famoso tópico ('La crueldad de cualquier mal o congoja más se calma o alivia diciéndola que callándola' $)^{15}$. La quintilla, por consiguiente, podría editarse con esa enmienda para entender "mal" en la acepción de 'difícil-

me reté, ço és que yo no·m parle [...] Per ventura lo coratge teu, volent alguna cosa, no pot parlar? Fedra diu, prenent similitut: 'La voluntad quieta parla co que vol, ço és sense ímpetu, e lo gran voler es baÿment calla’, co és, lo voler impetuós no permet parlar” (Séneca, 1995: 267).

14 En el siglo XIX, los autores de un diccionario afirmaban que los versos ilustraban "the silence that belongs to severe affliction" para a continuación parafrasearlos: "Seneca ha observed that light griefs are loquacious, but that deep sorrow has no tongue; in others words, that those who have Little to grumble about can bawl loud enough, while on the other hand, hose whose cup of sorrow is full to o'erflowing muse o'er their griefs and say not a Word" (Anónimo, 1838: 98); a principios de siglo XX, Montero interpretaba los versos en cuestión en los siguientes términos: "Es fácil expresar las emociones ligeras; las profundas se callan" (1922: 168); y ya en nuestro siglo, en Ipse dixit. Frases latinas (Barcelona, 2016), Zanoner daba una explicación similar: "La expresión se puede entender tanto en el sentido de que no se habla de forma espontánea de grandes dolores como que estos son tan fuertes que no se encuentran las palabras para describirlos" (2016: 499). Incluso la cita fue usada en manuales sobre trastornos mentales, como la Mental Hygiene ora $n$ examination of the intellect and passions (Edinburgo, 1844) de William Sweetser, para ilustrar que no pueden darse voz a "the deepest inward sufferings" (1844: 36), o como el de José Frank, para significar que "la tristeza verdadera y profunda es muda" (1843: 25).

15 Para el origen y difusión del tópico, con muchos ejemplos, véase Morros (1995: 148-149, n. 142, y 476-477). 
mente, apenas' y los versos en cuestión como 'La crueldad de mis males difícilmente se puede callar, disimular, ocultar, calmar, aliviar, al decirla':

La crueza de mis males mal se calla en la dezir, pues mis dichos no son tales, que igualen las desiguales congoxas de mi vevir (vv. 91-94).

En las primeras coplas reales o quintillas dobles el poeta insiste en esta idea de intentar expresar su dolor pero no poder por impedírselo una fuerza mayor, que en su caso es la tristeza (incluso llega a describir un proceso inverso al de Fedra al proponerse callar sin poder retener en semejante esfuerzo suspiros y lamentos):

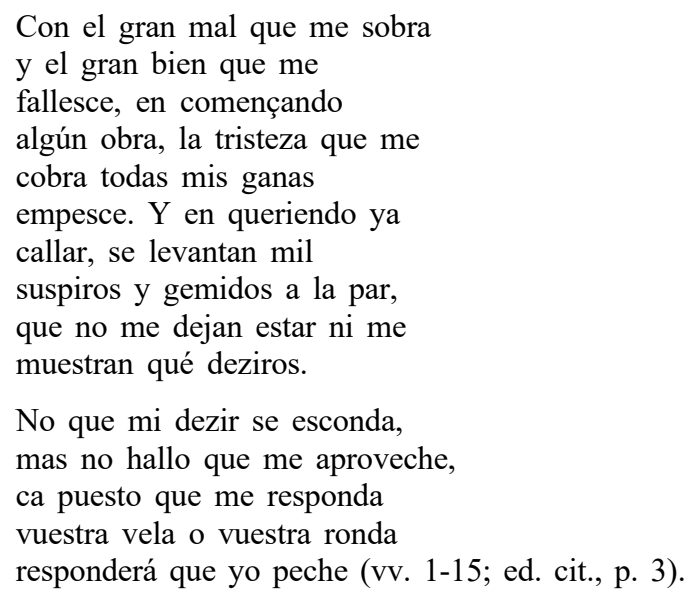

En esta última quintilla Manrique aduce otra razón para decidir callar y no hablar: la falta de respuesta por parte de su dama. Es evidente que el poeta sufre el mal de ausencia por haber sido su dama puesta bajo vigilancia o control por su marido, como lo hacen pensar los términos "vela" y "ronda", encargados de la función del espía o guardador en la lírica trovadoresca. Los vigilantes de la dama son los que informan al amante de que ha de pagar el tributo de su amor por ella en forma de sufrimiento. Por eso considera que poder expresarlo tampoco le va a aprovechar o servir para mitigarlo por la respuesta que espera y por la imposibilidad de acercarse a su amada. En una esparsa Manrique utiliza el adverbio de cantidad "más" junto al verbo "callar" pero para transmitir la idea contraria a la analizada en este trabajo. En ese caso la decisión de hablar tampoco le ha reportado ningún beneficio porque al tomarla ha causado el enojo de su dama. En esa tesitura reconoce que de haber callado más de lo que llegó a callar habría muerto:

Porque alguna vez hablé, halléme de ello tan mal, 
que sin dubda más valiera callar;

mas también callé,

y pené tan desigual,

que más callando muriera (vv. 7-12; Beltrán, 1993: 107).

La casuística amorosa de esta esparsa, en cualquier caso, es muy diferente a la de las coplas iniciales. En esta esparsa no se cuestiona en ningún momento el poder sedante de las palabras mientras que en las coplas sí se produce ese cuestionamiento: si las palabras o "dichos", por ineficaces, no pueden igualarse con los males poco van a servir para amortiguarlos y calmarlos, pero si se llegan a equiparar con ellos por atribuirles una eficacia que antes no tenían entonces sí pueden ejercer una función terapéutica de acuerdo con el famoso tópico. No conviene olvidar que Manrique en las coplas, leídas desde el punto de vista de Fedra, no llega a hablar porque cuando lo intenta más se calla. En ese supuesto, y solo en ese, el poeta no halla consuelo en las palabras porque carece de fuerzas para pronunciarlas y darles salida a través de la boca.

La enmienda que he propuesto podría justificarse, sin embargo, no solo por el sentido, las res, sino también por la forma, los verba, del pasaje. La enmienda restituye la figura retórica de la derivación, que el error había eliminado por completo: "males mal". La derivación es una figura retórica de dicción que alterna y a veces se confunde con la poliptoton y la figura etimológica: "dezir dichos" e "igualen las desiguales". El verso contiene otra poliptoton por antífrasis: "calla en la dezir"; y el verbo "callar", aparte el sentido de 'silenciar', tiene también el de 'disimular' y 'calmar' (por usarse para las aguas del río o del mar para indicar que se han sosegado), y solo el primero de ellos parece lógico si el verbo se introduce con el adverbio de cantidad "más" y no con el de modo "mal".

Las coplas se han conservado, como recordábamos al principio, en las dos primeras ediciones del Cancionero general preparadas por Hernando del Castillo (Valencia, 1511 y 1514), y entre las dos ediciones no se registran variantes demasiado significativas. En el pasaje en cuestión, sin embargo, hay una que podría interpretarse como errata sin duda favorecida por esa contradicción señalada entre la primera y la segunda parte de la redondilla. El componedor o cajista de la segunda edición pudo cometer un error mecánico al coger del cajetín el tipo con la vocal para la palabra "dichos", pero no cabe descartar que eligiera a propósito la "a" en vez de la "o" pensando en el sentido de toda la estrofa:

La crueza de mis males más se calla en la dezir, pues mis dichas no son tales, que igualen las desiguales congoxas de mi vevir ${ }^{16}$.

\footnotetext{
${ }^{16}$ La variante la recoge Beltrán (1993: 180).
} 
El componedor debió reparar en el contrasentido del pasaje y creyó que el error estaba en el género de "dichos": si la crueldad de los males se callaban con decirlos, los dichos no podían ser el sujeto de "son" al no equipararlos en ningún caso con esos males que con su intervención en forma de palabras habrían callado. Para el componedor la solución pasaba por buscar un antónimo de males que justificase su inferioridad, y la halló también de manera muy fácil al convertir el sustantivo "dichos" en el femenino "dichas". Ese cambio revela e indica claramente la anomalía del pasaje que ha pasado inadvertida al resto de editores del poema.

La expresión "mal se calla" la he documentado en un contexto similar en la obra de un poeta nacido a finales del siglo XV y que había leído muy bien el Cancionero general. El poeta en cuestión es Cristóbal de Castillejo y emplea esa expresión en la glosa del mote "Quien calla y sirve/ mucho pide", incluido en sus Obras de amores:

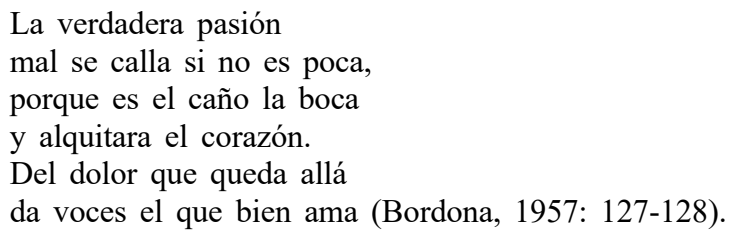

Castillejo desmiente la afirmación de Séneca al considerar que el sufrimiento (pasión), a no ser que sea leve o poco, difícilmente puede silenciarse, pero ilustra la expresión que he supuesto usada por Manrique exactamente en sus mismos términos. El poeta de Ciudad Rodrigo refuerza el tópico identificando el corazón, sede y almacén del sufrimiento, con la alquitara y la boca, lugar en el que se articulan las palabras, con el caño por el que sale el líquido destilado: equipara el sufrimiento con un proceso de destilación porque el dolor y el líquido del alambique necesitan por igual salir al exterior con una forma muy diferente a la de su origen. La conclusión es, por tanto, exactamente la contraria a la de Séneca y Manrique: el sufrimiento leve puede callarse, pero no el grande.

Juan Boscán, de la misma generación de Castillejo, pero más innovador que él, gran lector de la obra de Manrique, como lo demuestran las glosas a algunas de sus canciones, compuso unas coplas coincidiendo con su decisión de comunicar sus males después de haberlos callado durante mucho tiempo. El problema que le plantea esa decisión es que tampoco puede llevarla a cabo al tener sus males unas características que los hacen inabarcables para llegarlos a expresarlos todos juntos y a la vez:

Mi vida, para pasarla, téngola de publicar; es imposible callarla, 


\author{
y si la quiero contar, \\ tampoco puedo contalla. \\ Mis penas haze el amor \\ iguales de una manera: \\ no sé cuál da más dolor, \\ pero siempre la postrera \\ me parece que es mayor (vv. 11-20; Clavería, 1992: 55).
}

Por ese motivo Boscán tampoco halla consuelo a la hora de publicar y decir sus males. Una vez ha publicados o dichos unos aparecen otros nuevos aún mayores y más dolorosos que los anteriores que también necesitan publicarse y decirse:

Soy, en dezir mi cuidado, tan confuso y tan perdido, que, cuando un mal he contado, más quisiera haber seguido tras aquél que me he dejado (vv. 21-25; ibíd.).

El poeta barcelonés tampoco puede callar sus males al decirlos porque sus males son infinitos y no hay manera de callarlos porque tras decir unos siempre quedan otros para ser dichos. Por ese motivo solo halla una solución: ir detrás del mal que ha dejado de decir o contar porque ese mal, por no haber sido dicho o contado, ha de dolerle más. En el manuscrito Lastanosa-Gayangos el último verso se copia con una ligera variante, que podría ser difficilior: "tras aquel que me ha dejado". Es posible que en esta versión la copla tenga más sentido porque el poeta daría a entender que desea ir detrás del mal que le ha abandonado tras haberlo ya dicho o confesado: por su condición de ya dicho, este mal ya no le dolería, y su deseo de seguirlo sería perfectamente comprensible para dejar de sufrir. El texto de las ediciones por tanto parece introducir una lectio facilior por la atracción de la misma construcción unos versos antes: "un mal he dejado" (v. 23).

En la quintilla doble Manrique parece establecer una relación causa efecto al narrar su muerte como si fuera la del mártir san Vicente de Valencia: el martirio y el abandono de su cuerpo en medio del campo a merced de las fieras. La narración de su propia muerte certifica precisamente que la comunicación de sus males, en efecto, no le ha reportado ningún tipo de alivio: teniendo controlada la crueldad de esos males sería difícil justificar su muerte como consecuencia del martirio (en una de las esparzas mencionas arriba el poeta especula con la posibilidad de que "más callando muriera"). En esa quintilla parece haber un error muy evidente, pero conviene releerla para comprobar si realmente es así:

Mas después de atormentado con cien mil agros martirios, diré cuál amortajado queda, 
muerto y no enterrado, a escuras, sin luz ni cirios,

cual aquel cuerpo sagrado, de san Vicente bendito, después de martirizado, a las fieras fue lançado por cruel mando maldito (vv. 96-105; Morros, 2005b: 7-8).

Todo el pasaje es anómalo y exige una corrección, además de un cambio en la puntuación. En los dos casos el problema radica en la identificación del sujeto: en el primero para "queda" y el segundo para "fue lançado". González Cuenca se percató de esas dos anomalías, y para la primera creyó que los editores modernos la mantenían por considerar el sujeto de "queda" "mi vevir", pero al tenerla por "una solución un tanto violenta" propuso otra que le parecía mucho mejor: la suposición de "cuál" no como pronombre exclamativo sino como adverbial ("cual") en correlación con el "cual" de la estrofa siguiente. Para hacer comprensible el pasaje aclara que "amortajado" vale por 'hombre amortajado':

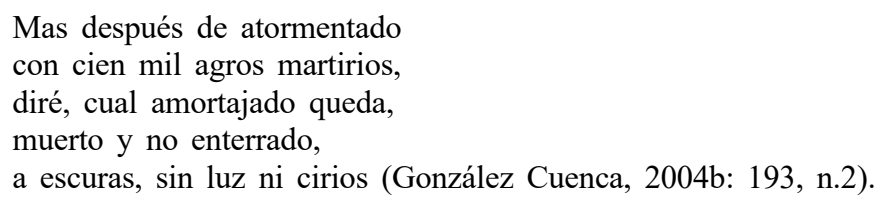

Tampoco esta solución solventa el problema porque un participio pasado no puede ser el sujeto de un verbo, y en este caso "amortajado" depende directamente del verbo "quedar", al igual que "muerto" y "no enterrado". La solución es mucho más sencilla y la aporta el mismo texto en unos versos anteriores. Para conseguir que el pasaje tenga pleno sentido solo conviene cambiar la persona y el tiempo de "queda" porque el sujeto de ese verbo no puede ser otro que el cuerpo del poeta. El verbo debe ponerse en primera persona y en pretérito, en correlación con el "quedé" del verso 86 , exactamente con la misma construcción. Nuestro poeta establece una clara gradación al narrar el estado en que queda primero tras la separación de su amada y después tras no poder desahogarse con las palabras:

Cuál quedé yo quedando, no hay mano que lo escriba $[\ldots]$

diré cuál amortajado quedé, muerto y no enterrado,

La segunda anomalía ya la solventó correctamente González Cuenca al hacer coincidir el final de la oración con el final de la segunda quintilla de la estrofa 
(2004b: 192-193). Para marcar esa doble coincidencia puso un punto y aparte después de "cirios" y no la coma que le habían puesto otros editores. Las dobles quintillas objeto de este análisis, por tanto, deberían editarse de esta manera:

Mas después de atormentado con cien mil agros martirios, diré cuál amortajado quedé, muerto y no enterrado, a escuras, sin luz ni cirios.

Cual aquel cuerpo sagrado de san Vicente bendito, después de martirizado, a las fieras fue lançado por cruel mando maldito; mas otro mando mayor de Dios, por quien padeció, le envió por defensor un lobo muy sin temor y un cuervo que le ayudó.

En la "finida" Manrique completa la comparación que ha iniciado en la segunda quintilla que acabamos de analizar:

Así guardan mi persona

por milagro, desque he muerto, un león con su corona $\mathrm{y}$ un cuervo que no abandonada mi ser hasta ser despierto (vv. 111-115; Morros, 2005b: 8).

Entre esta primera quintilla de la "finida" y la segunda de la estrofa objeto de nuestras enmiendas ha reservado una doble quintilla entera para exponer el caso del santo que ha empleado en los dos símiles (la muerte a causa de martirio y la exposición de su cuerpo, por no darle sepultura, a merced de las fieras). Esta doble quintilla es desde el punto de vista sintáctico independiente de las otras dos, anterior y posterior, a las que sirve como elemento de comparación, y tiene por tanto una unidad en sí misma y es introducida por el adverbio "Cual", en exacta correlación con el "Asì" que encabeza la "finida" (puntuado y entendido de este modo el pasaje no hay duda de que el sujeto de "fue lançado" es "aquel cuerpo sagrado"):

Cual aquel cuerpo sagrado [...]

a las fieras fue lançado [...]

Así guardan mi persona

En la comparación de la "finida" puede aludirse a una intervención de la amada en un papel semejante al de Dios con el cuerpo abandonado del san 
Vicente. El poeta y el santo han padecido sus respectivos martirios, el primero por amor a su dama y el otro por amor a Dios, y por tanto si en un caso ha sido Dios quien ha decidido salvaguardar el cuerpo de su súbdito con un lobo y un cuervo, también cabe pensar que ha sido la dama del poeta, con la misma intención, quien ha mandado otros dos animales. Al mandarle un león en vez de un lobo la dama parece garantizar su regreso y la resurrección del poeta pues la leona, identificada con la Virgen María, fue el animal relacionado con la resurrección por la capacidad que se le atribuía al macho de devolver a la vida con solo su aliento a las crías que habían nacido muertas: el león daba vueltas en torno al cadáver rugiendo para resucitarlo al tercer día ${ }^{17}$. En esos mismos bestiarios, como el de Philippe de Thaün, se relaciona al león con Jesucristo por ser el león un animal que duerme con los ojos abiertos para proteger a los suyos:

Y sabed otra actitud del león; es de tal índole, que duerme con los ojos abiertos. Sabed que esto representa al Hijo de la Virgen María, mientras velaba en su muerte (Malexecheverría, 1986: 27).

Esas son las dos razones por las que la amada ha elegido un león y no el lobo que Dios mandó para proteger al santo: la dama, en el papel de la virgen María, devolverá al poeta a la vida no con su aliento sino con su presencia, y en ese papel le ha mandado a su hijo, el león, para que lo vele en su muerte con la intención de vencerla.

En las páginas anteriores hemos llamado la atención sobre una serie de lugares críticos de las coplas que suelen encabezar el cancionero amoroso de Jorge Manrique para proponer soluciones a los problemas que esos lugares plantean tanto desde el punto de vista del sentido como también de la sintaxis. Las dos enmiendas creo que son necesarias (quizá una más que otra) para ofrecer un texto más cercano al de la voluntad del autor, y las dos se han introducido con las herramientas que la ecdótica más fiable y también tradicional (por supuesto, no infalible) pone a la disposición de todos los editores de textos literarios. La primera de las dos, la más importante y difícil de aceptar, no sólo está reforzada por el sentido de la quintilla sino también avalada como lectio difficilior

\footnotetext{
${ }^{17}$ El Physilogus es el primer texto de esta naturaleza que recuerda esta propiedad del león y la leona: "Cum leena parit catulum, generat eun mortuum et custodit eum mortuum tribus diebus, donec veniens pater eius die tercio insufflet in faciem eius et vivificet eum./ Sic omnipotens pater Dominum nostrum Iesum Chistum filium suum tercia die suscitavit a mortuis" (Morini, 1996: 12); Philippe de Thaün lo sigue de manera bastante literal: "Sabed que la leona trae al mundo a su cahorro muerto; y cuando lo tiene, llega el león, que tantas vueltas da en torno suyo, rugiendo, que al tercer día el cachorro resucita. Sabed que la leona representa la Virgen María, y el leoncillo a Cristo, que murió por los hombres" (Malaxecheverría, 1986: 28). En mi edición del poema ya recordé esta propiedad del león para entenderlo mejor (Morros, 2005b: 8).
} 
y por el usus scribendi no del propio autor sino de otro, si no contemporáneo, porque no lo era, al menos formado en la misma escuela poética. La segunda enmienda es más evidente y está garantizada además por la constitutio textus (la correlación evidente entre "Cuál quedé yo quedando" y "diré cuál amortajado quedé" $)^{18}$. Es una práctica ecdótica, la usada en este trabajo, tan antigua como la misma literatura y que los humanistas reivindicaron para recuperar un mundo que creían perdido por la incompetencia de los copistas medievales.

\section{BIBLIOGRAFÍA}

Anónimo (1838): A New Dictionary of Quotations from the Greek, Latin and Modern Language, London, Lippincott.

Anónimo (1864): Directorio de bien morir. Ejercicios que practica la Ilustre y Venerable Congregación de Nuestra Señora de la Buena Muerte, Barcelona, Imprenta de los herederos de la viuda Pla.

Beltrán, Viçenç (ed.) (1991): Coplas que hizo Jorge Manrique a la muerte de su padre, Barcelona, PPU.

Beltrán, Viçenç (1992): “Tipología y génesis en los cancioneros. El caso de Jorge Manrique”, en Rafael Beltrán, José Luis Canet y José Luis Sirera (coord.), Historias y ficciones. Coloquio sobre literatura del siglo $\mathrm{XV}$, Valencia, Universitat.

Beltrán, Viçenç (ed.) (1993): Jorge Manrique, Poesía, Barcelona, Crítica.

Beltrán, Viçenç (2016): “Los sentidos humanos ¿conservados u olvidados?”, Revista de Lexicografia, XXII, pp. 73-92, <https://doi.org/10.17979/rlex.2016.22.0.3320>.

Blecua, Alberto (1983): Manual de crítica textual, Madrid, Castalia.

Blüher, Karl Alfred (1983): Séneca en España. Investigación sobre la recepción de Séneca en España desde el siglo XIII hasta el siglo XVII, Madrid, Gredos.

Bordona, Domingo (1957): Cristóbal de Castillejo, Obras, II, Madrid, Espasa-Calpe.

Burrieza Sánchez, Javier (2004): "Los ministerios de la Compañía”, en Teófanes Egido (coord.), Los jesuitas en España y en el mundo hispánico, Madrid, Marcial Pons, pp. 107-150.

Byrne, Susan (2015): Ficino in Spain, Toronto, University of Toronto Press,

Chicharro, Domingo (ed.) (1999): santa Teresa de Jesús, Las moradas del castillo interior, Madrid, Biblioteca Nueva.

Clavería, Carlos (ed.) (1992): Juan Boscán, Las obras de Boscán de nuevo pía y repartidas en tres libros, Madrid, Cátedra.

Conde, Juan Carlos (2009): "Conservados/ olvidados: una copla de Manrique y los límites del método neolachmanniano", Incipit, XXIX, pp. 59-84.

Dutton, Brian (1982): Catálogo-índice de la poesía cancioneril del siglo XV, Madison, Hispanic Seminary of Medieval Studies.

Frank, José (1843): Patología interna, Madrid, Señora viuda de Calleja e Hijos.

Gago Jover, Francisco (ed.) (1999): Arte de bien morir y Breve confesionario, precedido de Las palabras de la muerte de Enrique Lázaro, Palma de Mallorca, Universitat de les Illes Balears, José J. de Olañeta.

Glaser, Edward (ed.) (1967): Héctor Pinto, Imagen de la vida cristiana, Barcelona, Juan Flors.

\footnotetext{
${ }^{18}$ Para la emendatio y las herramientas para practicarla con bastante fiabilidad, véase Blecua, 1983: 123-136 y Zavala, 2007: 45-46.
} 
Glixelli, Stefan (1914): Les cinq poèmes des trois morts et des trpois vifs, Paris, Librairie Ancienne Honoré Champion.

Gómez Moreno, Ángel (2000): Jorge Manrique, Poesía completa, Madrid, Alianza Editorial.

González Cuenca, Joaquín (2004a): “Introducción”, en Hernando del Castillo, Cancionero General, I, Madrid, Castalia, con el patrocinio de la Generalitat Valenciana.

González Cuenca, Joaquín (2004b): Hernando del Castillo, Cancionero general, II, Madrid, Castalia.

Infantes, Víctor (1997): Las danzas de la muerte. Génesis y desarrollo de un género medieval (siglos XIII-XVII), Salamanca, Universidad.

Malaxecheverría, Igmacio (1986): Bestiario medieval, Madrid, Siruela.

Matilla Tascón, Antonio (1983): Testamentos de 43 personajes del Madrid de los Austrias, Madrid, Instituto de Estudios Madrileños.

Montero, Belisario J. (1922): Ensayos sobre filosofía y arte, Buenos Aires, Schenone y Linari.

Morel D’Arleux, Antonia (1990): “Los tratados de preparación a la muerte: aproximación metodológica”, en Manuel García Martín (coord.), Actas del II Congreso de la Asociación Internacional del Siglo de Oro, II, Salamanca, Ediciones Universidad de Salamanca, pp.719-734.

Morini, Luigina (1996): Bestiari medievali, Torino, Einaudi.

Morrás, María (ed.) (2003): Jorge Manrique, Poesía, Madrid, Castalia.

Morros, Bienvenido (ed.) (1995): Garcilaso de la Vega, Obra poética y textos en prosa, Barcelona, Crítica.

Morros, Bienvenido (2005a): "Manrique y Petrarca. Estudios del petrarquismo en la literatura del siglo XV", Medioevo Romanzo, XXIX, pp. 132-156.

Morros, Bienvenido (ed.) (2005b): Jorge Manrique, Poesía, Barcelona, Vicens Vives.

Morros, Bienvenido (en prensa): "El comendador Escrivá y Ángel González esperando la muerte", Boletín de la Real Academia Española.

Parrilla, Carmen (ed.) (1995): Diego de San Pedro, Cárcel de amor, Barcelona, Crítica.

Revuelta González, Manuel (2008): La compañía de Jesús en la España contemporánea. Tomo III: palabras y fermentos (1868-1912), Madrid, Universidad Pontificia Comillas.

Séneca, Lucio Anneo (1832): Opera tragica, II, Paris, Nicolaus Eligius Lemaire.

Séneca, Lucio Anneo (1995): Tragèdies, ed. Tomás Martínez Romero, I, Barcelona, Barcino.

Serés, Guillermo (1996): La transformación de los amantes: imágenes del amor de la antigüedad al Siglo de Oro, Barcelona, Crítica.

Solà-Solé, Josep M. (1981): La dança general de la muerte, Barcelona, Puvill.

Sweetser, William (1844): Mental Hygiene or an examination of the intellect and passions, Edinburgh, Maclachlan, Stewart \& co.

Villa Ardura, Rocío de la (1986): "Introducción”, en Marsilio Ficino, De amore. Comentario a "El Banquete” de Platón, Madrid, Tecnos.

Zanoner, Angela María (2016): Ipse dixit. Frases latinas, Barcelona, De Vecchi.

Zavala, Lauro (2007): De la investigación al libro: estudios y crónicas de bibliofilia, Ciudad de México, UNAM.

Fecha de recepción: 28 de noviembre de 2017

Fecha de aceptación: 5 de marzo de 2018 